\title{
The Interaction Of Documentation Format And Sequence On Error Detection In A Sales Returns Accounting Information System
}

Vincent Owhoso (Email: vowhoso@bentley.edu), Bentley College

\begin{abstract}
This paper describes an experiment investigating whether the documentation mode and sequence of documentation jointly affect error detection performance when documenting an accounting information system. Forty-six graduate and undergraduate accounting and accounting information systems students participated in the study in three groups. The students received a narrative and flowchart describing a client's sales returns processing system and were asked to identify the control weaknesses and violations in the system. One group of participants received both the narrative and flowchart simultaneously. Another group of participant received the narrative first followed by flowchart after a period of time and a third group received flowchart first followed by narrative after a period of time as well.

The results show that neither narrative nor flowchart was differentially effective than the other in detecting system control errors. However, there was a significant interaction of documentation format and documentation sequence, suggesting that the amount of error detection when documenting a system was dependent upon the format and the sequence in which documentation was conducted. It also seems that given a choice of documentation formats to use, participants prefer to use narrative primarily more than flowchart in documenting a system. When forced to use flowchart first followed by narrative, participants' overall error detection performance improved significantly than when using narrative first followed by flowchart. The implication in this study is that a second documentation format goes a long way to detect errors that would otherwise not be detected. Similarly, the degree to which errors are effectively detected depended on the sequence in which documentation format is used.
\end{abstract}

\subsection{Introduction}

iven the advances in information technology, importance of internal control systems to the audit, and current competitive audit environment, audit firms are finding better ways to conduct high quality audits in a cost-effective manner. However, auditors may be sacrificing audit quality if they focus largely on costsaving objectives. For example, auditors could sacrifice audit quality by documenting internal control systems using a single documentation format. By using a single system documentation format such as narrative or flowchart, auditors would be ignoring the potential advantages of additional documentation in improving internal control system's effectiveness. The use of additional system documentation method could in fact detect additional material control errors in the system that would otherwise not be detected. However, if auditors use two or more documentation formats to document internal control systems, they could achieve high quality audits at the expense of high audit costs because using two or more documentation formats may not be cost-effective (Purvis 1989).

Readers with comments or questions are encouraged to contact the author via email. 
Nonetheless, two or more documentation formats are believed to be differentially effectiveness in documenting a system better because they are likely to complement one another. For example, a flowchart is likely to complement a system narrative or questionnaire in detecting system control errors because each of the two formats document different aspects of a system better than the other.

Two issues that have not been examined in the system documentation literature are the degree to which additional documentation and documentation sequence would be incrementally beneficial in detecting control weaknesses or violations in a client's accounting system. These issues are important for a number of reasons. It appears that auditors are adopting narratives and questionnaires as the internal control systems documentation methods of choice rather than system flowcharts (Bierstaker and Brody 2000). Since auditors traditionally use narrative and/or flowchart as system documentation tools, the benefits of documenting a system using flowcharts may be lost if auditors are no longer being trained to document systems using flowcharts. Not using flowchart may result in the future shortage of qualified auditors with flowchart documentation experience when reviewing the work of subordinates. Further, the increasing advances in information technology (IT) are bringing changes to the nature and complexity of clients' internal control systems and these changes are affecting the structure of internal control systems evaluation tasks (Curtis and Borthick 1999; Davis 1996). For example, (Curtis and Borthick1999) noted that the internal control evaluation task is no longer a documentation of transaction flows, rather it has become a documentation of those control objectives having direct impact on specific financial statement assertions. At the same time, businesses are trending towards outsourcing their internal audit functions to external audit firms. This implies that the internal audit functions at these businesses would be taken over by external audit firms (Bierstaker and Brody 2000) and thus requiring them to design (or redesign) and document the businesses' accounting systems during normal audits or consulting engagements. Unless narratives or other documentation formats are independently equally effective as system flowcharts, educators may be ill-prepared for training auditors for future evaluation and documentation of IT systems, because graduates would lack technical proficiency ${ }^{i}$ for effectively evaluating and documenting accounting systems.

The purpose of this study is to examine the incremental value of system documentation format and the interaction of documentation format and sequence when documenting a system for control weaknesses and violations using system narrative or flowchart or a combination of both narrative and flowchart. Incremental value is measured by whether narrative or flowchart independently increases auditors' detection of control weaknesses and violations in the client's sales returns accounting system in a complementary manner. The study extends the literature on presentation mode, presentation order, and error detection by presenting subjects with the system narrative and flowchart of a client's sales returns processing system in three different ways (narrative followed by flowchart, flowchart followed by narrative, and both narrative and flowchart combined). The subjects were then asked to identify the control weaknesses and violations in the system.

This study is different from other studies in three aspects. First it uses a set of identical information that differs only in presentation format - it uses a system narrative and a flowchart that is an interpretation of the narrative. Second, the subjects are a homogeneous group and the task representation is matched with the task that the subjects are being asked to perform. Third, for each task representation, each subject is asked to identify control weaknesses in the client's sales return subsystem, using two separate documentation formats, independently or combined.

The results show an interaction effect of format and sequence but no main effect of format or sequence, suggesting that participants' detection of system control errors improved depending upon the documentation format used and the sequence it was used by the participants. The results also suggest that a system narrative or flowchart alone is not sufficient in detecting a system's control violations because each format had an incremental value that complements the other. The results thus point to the need to use more than one documentation method in the same audit and to pay attention to the documentation sequence in order to effectively enhance detection of system control errors, since the sequence could affect the amount of error detected. 
These findings have implications for audit practice, teaching, and research. By using more than one documentation method, auditors' ability to identify more system control weaknesses and violations during the audit would be enhanced and the system would have high quality data with integrity. This would mean that systems would be reliable with integrity, so that high quality financial and non-financial reports are being generated from the system. Identifying more system control errors could lead to the reduction of potential litigation that could arise as a result of system failures in the new economy. Additionally, educators in AIS could emphasize the importance of documenting systems with flowcharts in the classroom, and emphasize specifically, the strengths and limitations of each documentation format using real life examples of how each format can focus on different aspects of system controls.

The paper is organized as follows. Development of research questions is presented in the next section. Then the research method and results sections are presented. Finally, a summary and conclusion with further research are provided in the last section.

\subsection{Development of Research Questions}

\subsection{The Incremental Value of Narrative and Flowcharts}

Traditionally, many accounting firms required auditors to evaluate a client's internal controls by preparing flowcharts when documenting transaction flows. However, with SAS 78 (AICPA 1996), the format for evaluating or documenting internal control systems during the audit was left to the individual auditor. Purvis (1989) suggests that documentation formats impose different degrees of structure on the auditor's performances, because each format emphasizes different aspects of a client's internal control system. Questionnaires are said to emphasize specific controls and are comprehensive in covering procedural, organizational and informational control issues. However, they fail to relate individual controls to one another (Arens and Loebbecke 1997) and are susceptible to the risk of being used mechanically. They also suffer from insufficient adaptation to client operations, inadequate attention to the meaning of individual control plans or client's responses, and respondents' incomplete careful consideration of individual questions (Wallace 1995).

Narrative is a concise written memorandum of an accounting information system that describes a client's audit objectives or system processes and the controls that meet those objectives or processes. Narrative also describes the origin of documents and record of the document in the accounting information system, the processing steps, disposition of documents in the system, and controls in place regarding the document or processing steps. However, narratives are written from the preparer's understanding or perception of the system and thus subject to interpretations.

Flowchart is a graphical representation of a client's system and documents, including the sequential procedural flows of information throughout the system and the organizational controls involving those documents in a detailed manner. Flowchart describes a process by graphically displaying the process steps in proper sequence, identifies critical process points for control, and suggests areas for further improvement.

Empirical evidence also supports the notion that documentation format will affect auditors' effectiveness in documenting a system. Purvis (1989) found that documentation formats affect auditors' effectiveness when collecting data, with more data being collected using questionnaires and narratives than flowcharts. Further, Bierstaker (1995) asked groups of auditors to read narrative and update or complete a partial flowchart and then perform cued and uncued internal control evaluations from memory. He reported that auditors who received a narrative and updated flowchart recalled more control errors. Recently, Curtis and Viator (2000) noted that when auditors evaluate control weaknesses or violations from memory they seem to use both control objectives and transaction flows, suggesting that auditors internalize more than one documentation format. Although Purvis (1989) and Bierstaker (1995) did not explicitly examine the incremental value of flowchart over narrative or vice versa, each format is likely to add value to a system documentation task in a complementary manner. Because narrative or flowchart documents different aspects of a system, each format is likely to document different aspects of the system better than the other and thus 
would detect additional system control errors when used as a second documentation tool. Consequently, the total amount of detected control errors as a result of using narrative or flowchart as a second documentation tool would be more when compared to the total amount of errors detected by using either narrative or flowchart alone. This analysis leads to the following proposed research questions based on the experimental design presented in Table 1 .

Table 1: Experimental Design

\begin{tabular}{|c|c|c|c|}
\hline \multicolumn{4}{|c|}{ Documentation Format } \\
\hline Documentation Sequence & Narrative & Flowchart & Total \\
\hline Both Narrative and Flowchart & $\mathrm{A}$ & $\mathrm{B}$ & $\mathrm{X}$ \\
\hline Flowchart then Narrative & $\mathrm{C}$ & $\mathrm{D}$ & $\mathrm{Y}$ \\
\hline Narrative then flowchart & $\mathrm{E}$ & $\mathrm{F}$ & $\mathrm{Z}$ \\
\hline
\end{tabular}

RQ1: Is the amount of detected control errors when documenting an accounting information system different if narrative is used versus flowchart (or is $\mathrm{D} \neq \mathrm{E}$ )?

RQ2: Does using narrative or flowchart as a second system documentation tool result in more detected system control errors, regardless of the initial documentation tool used (or are (Y - D > 0) and (Z - E > $0))$ ?

\subsection{Interaction Effect of Documentation Format and Sequence}

The sequence in which narrative or flowchart is used in documenting a system can affect the amount of detected control errors. This arises because each format documents some aspects of a system better than the other. Empirical evidence largely reports that task variables affect decision-making strategies and the same variable can result in a different decision depending on the order in which the variable was presented (Payne et al.1990). Accordingly, order effect is said to result from the interaction between information processing strategies and task variables (Einhorn and Hogarth 1992) ${ }^{\text {ii }}$. However, order effect research to date is at best mixed. For example, Monroe and $\mathrm{Ng}$ (2000) do not find recency effects for seniors and managers in an inherent risk task but Arnold et al., (2000) found recency effects for partners and managers in a going concern task, and for partners and managers in an insolvency case.

Consequently, documenting using flowchart first followed by narrative versus documenting a system using narrative first followed by flowchart could result in differential error detection performance. Because flowchart is a graphical representation of the sequence, processing steps, and critical control points for information flow for a system, individuals documenting a system using flowchart may encode the graphical model of the system (as opposed to a textual model) and retrieve it from memory differently. Newell and Simon (1972) suggest that the form in which a problem is expressed is believed to affect problem-solving strategy. By representing the graphical model of the system in memory, participants can spatially access the system as a single unit (Plumlee 1985), and this would make the system and the business processes within the system easier to understand. Thus, if participants use flowchart first followed by narrative to document a system, they are more likely to detect a larger amount of errors when using the flowchart and still detect a larger amount of incremental errors when they later use narrative to document the system. As noted earlier, by using flowchart first, participants would likely represent the mental model of the system in memory. This mental graphical model would likely interact with the textual description of the system and its controls to bridge the missing link between any previously unidentified control errors when flowchart was used. Because of the likely interaction of the mental model and the textual description of the model, a larger amount of errors would be detected using flowchart first followed by narrative.

However, if participants use narrative to document a system first followed by flowchart, they are likely to effectively detect a significant amount of the control errors with the narrative alone before detecting additional errors 
using the flowchart as a second documentation tool. Essentially, the incremental effect of flowchart having used narrative before may be smaller than the incremental effect of narrative having used flowchart before. This arises because textual language is the next order of communication between two or more parties, second to verbal communication. Thus, participants are likely to be more effective in detecting a larger amount of errors if narrative were used first, followed by flowchart than if flowchart were used first followed by narrative.

If participants document a system using both narratives and flowcharts at the same time, they are more likely to detect many more system control errors than either using the "flowchart first followed by the narrative" or "narrative first followed by flowchart" sequence. This arises because by using both the narrative and flowchart combined, participants could iterate between the two documentation formats. Further, since narratives and flowcharts are specifically effective in documenting different aspects of a system, participants could read the system narrative and look over the flowchart to enhance their understanding of the system at the same time. This simultaneous exposure to the two documentation formats is likely to enhance the participants' understanding and detection of more system control errors than either "narrative then flowchart" or "flowchart then narrative" method. Based on this analysis the following research questions are proposed.

RQ3: Does documenting a system using both narrative and flowchart combined result in more detected system control errors than documenting a system with flowchart

followed by narrative or with narrative followed by flowchart. Does documenting a system with flowchart followed by narrative detect more control errors than documenting with narrative followed by flowchart (or is $\mathrm{X}>\mathrm{Y}>\mathrm{Z}$ )?

RQ4: Is the amount of detected system control errors during system documentation dependent upon the documentation format and sequence used?

\subsection{Method}

\subsection{Subjects}

To analyze the research questions, 46 graduate and senior undergraduate accounting or accounting information systems students ( 2 students reported MIS major) evaluated a case about a client's sales returns processing system for system control errors and violations. The students were all enrolled in the undergraduate and graduate advanced accounting information system's course taught by a professor other than the researcher. The participants have also completed the first course in accounting information systems either at the graduate or the undergraduate level in a previous semester, have completed the auditing course, or were taking the course at the time the test was administered. Several of the students had also taken other accounting and CIS courses or were enrolled in these courses at the time of the experiment. The subjects were randomly assigned to one of three sequence manipulations, narrative then flowchart (17 students), flowchart then narrative (15 students), and narrative and flowchart combined (14 students). The average time to complete the task was pegged at 30 minutes-fifteen minutes each for the narrative and flowchart segments.

\subsection{Case Materials}

The case materials presented to the students described an electronics company in a metropolitan area and its efforts to control the increasing level of sales returns using Peachtree-based accounting information system. In each sequence, the company's background information, system narrative and system flowchart were described and presented to the subjects. The flowchart was an interpretation of the sales returns' system narrative. The experimental design shown in Table1 presents the evaluation format (narrative versus flowchart) and documentation sequence (narrative then flowchart, flowchart then narrative and narrative and flowchart combined) as independent variables and detection performance - percentage of detected errors is the dependent variable of interest. The format variable was a within subject factor variable. 
Three versions of the case were used to simulate the sequence variable. Version 1, henceforth (N-F sequence) presented the company background information, followed by the narrative and then the system flowchart. Version 2 (F-N sequence) presented the company background information, followed by the system flowchart and then the narrative. Version 3 (B-O sequence) presented the company background followed by the system narrative and flowchart combined. A blank working paper template was included in each narrative or flowchart section of the case material for subjects to record their responses. The case directed the students to identify the control weaknesses and errors and system violations in the sales returns processing system. The researcher intentionally planted eight system control errors by omitting relevant steps or details from the narrative and flowchart.

\subsection{Procedure}

The participants in each sequence grouping were told about the objective of the study. They were asked to read the instructions carefully and to record their responses as best as possible on the response sheet provided without help from anyone. The narrative and flowchart sections of each case version had a response sheet attached. Case versions 1 and 2 were produced on different color paper for ease of identification and data coding. Version 3 was produced on white paper with no separate colors for the narrative or flowchart sections.

The instructions to the subjects include the following. For those receiving the blue (version 1) or yellow (version 2) color coded case materials, there were two parts to the experiment, part 1 of the experiment will terminate in twenty minutes and then the material and your answers to part 1 would be collected. Part 2, which is a continuation of part 1 would then be presented to you and will be collected at the end of the experiment. Collecting the scores was necessary to separate errors detected when using one format from those detected when using another.

For those receiving white color-coded case materials (version 3), they were told that they could continue to work on the task but their case materials and solution would be collected only at the end of the experiment which was 30 minutes later. To make sure that errors detected by participants who received both narrative and flowchart at the same time were classified properly as flowchart and narrative errors, they were told to use an "N" notation if they identify errors when using the narrative section and an "F" notation if they identified errors when using the flowchart section for system documentation.

Participation in the study was made possible by the professor teaching the course who also introduced the experiment as an important exercise to the students. However, the researcher told the subjects that no names were allowed to be entered on the solution sheets since the identity of the participants was intended to remain anonymous.

\subsection{Dependent Variable}

The dependent variable was detection performance (DP) measured by the proportion of system errors and violations detected by the subjects in each sequence grouping. For example, to calculate DP for the "narrative then flowchart" sequence, the number of total errors detected was divided into the total number of errors available which was eight. As an illustration, if a participant detected three errors in the narrative section and two errors in the flowchart section of the "narrative then flowchart" sequence, a score of 0.375 would be recorded for the narrative section and 0.25 would be recorded for the flowchart section. Together, this participant would have detected 62.5 percent of the total system control errors. For each of the analysis that follows, this scheme was used to calculate the proportion of detected errors for each documentation sequence. Errors that overlap were counted as one incidence of error detection and recorded only in the section in which they were was first identified.

To determine the amount of system control errors detected by participants based on their recordings in the response sheets, two masters' degree students (one majoring in AIS and the other in Finance) who did not participate in the current study coded the participants' responses using the solution key provided by the researcher. The two students also had their first degrees in accountancy. 
The coders were asked to first work independently and then get together to reconcile their scores. They were encouraged to talk to the researcher if they had difficulty in reaching consensus. At the end of the coding task, the students turned in a final copy that contained the coded product. They indicated to the researcher that they encountered no difficulty in reaching a consensus.

\subsection{Results}

The system control errors that were identified by the participants and coded by the graduate assistants were analyzed using the general linear model (GLM). The GLM method is appropriate when cellblocks are unbalanced. Descriptive statistics are shown in Table 2. As shown in column 5 in Table 2, 49 percent of the total system control errors were detected with the combined use of both the narrative and flowcharts (B-O) to document the system's controls. However, $54 \%$ of the control errors were detected by using the "flowchart followed by narrative (F-N)" sequence method and only $42 \%$ of the system control errors were detected by using the "narrative followed by flowchart (N-F)" documentation sequence method.

Research Question (RQ)1 asks whether documenting a system with narrative results in more or less detected system control errors than documenting with flowchart. RQ1 was examined by conducting a separate GLM analysis that compared cell D and cell E in Table 1 and Table 2 for the main effect of format. As shown in Table 3, panel A, the main effect of format was not significant $(F=0.42 ; p<.524)$, suggesting that neither narrative nor flowchart documentation formats is differentially effective than the other in detecting system control errors. However, a look at Table 2 indicates that participants detected a slightly larger amount of errors using the narrative format (36\% in cell E) than the flowchart format (30.8\% in cell D). There was, however, a two-way interaction of format and sequence $(\mathrm{F}=16.50 ; \mathrm{p}<.000)$; this is shown in Table 3 panel $\mathrm{D}$ and analyzed later in this study.

Table 2: Descriptive Statistics

Cell means (std deviation)

Error Detection Performance when Documenting Sales Returns Accounting Information Systems Control Weaknesses and Violations

\begin{tabular}{|c|c|c|c|c|}
\hline \multicolumn{5}{|c|}{ FORMAT } \\
\hline Sequence & $\underline{\text { Narrative }}$ & Flowchart & $\underline{\mathbf{N}}$ & $\underline{\text { Total }}$ \\
\hline Both & $0.437(.228)$ & $0.054(.094)$ & $\overline{14}$ & $0.491(.252)$ \\
\hline $\mathrm{F}-\mathrm{N}$ & $0.233(.258)$ & $0.308(.221)$ & 15 & $0.541(.426)$ \\
\hline $\mathrm{N}-\mathrm{F}$ & $0.360(.233)$ & $0.059(.078)$ & 17 & $0.419(.257)$ \\
\hline
\end{tabular}

Table 3: General Linear Model Test Results

Panel A

$\overline{\text { Dependent Variable }}=$ Detection Performance Based on Documentation Format

\begin{tabular}{llllll} 
Source of factors & $D f$ & $S S$ & $M S$ & F-ratio & $p$-value \\
\hline Format -Model & 1 & 0.215 & 0.215 & 0.42 & 0.524 \\
Error & 30 & 1.5546 & 0.018 & &
\end{tabular}

\section{Panel B}

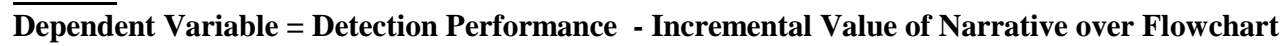

$\begin{array}{llllll}\text { Source of factors } & \text { Df } & \text { SS } & \text { MS } & \text { F-ratio } & \text { p-value } \\ \text { Narrative -Model } & 1 & 0.816 & 0.816 & 12.25 & 0.004 \\ \text { Error } & 14 & 0.933 & 0.066 & & \end{array}$




\section{Panel C}

$\overline{\text { Dependent Variable }}=$ Detection Performance - Incremental Value of Flowchart over Narrative

$\begin{array}{llllll}\text { Source of factors } & \text { Df } & \text { SS } & \text { MS } & \text { F-ratio } & \text { p-value } \\ \text { Flowchart -model } & 1 & 0.058 & 0.058 & 9.66 & 0.007 \\ \text { Error } & 1 & 0.097 & 0.006 & & \end{array}$

Panel D

Dependent Variable $=$ Detection Performance Based on Format and Sequence

$\begin{array}{llllll}\text { Source of factors } & D f & S S & M S & \text { F-ratio } & p \text {-value } \\ \text { Between factors } & 2 & & & 0.59 & 0.559 \\ \text { Sequence } & 43 & 0.061 & 0.061 & & \\ \text { Error } & & 2.219 & 0.052 & & \\ & & & & 16.50 & 0.000 \\ \text { Within Factors } & 2 & 0.891 & 0.445 & & \end{array}$

Legend:

Sequence $=(\mathrm{B}-\mathrm{O}),(\mathrm{F}-\mathrm{N}),(\mathrm{N}-\mathrm{F})$

FORMAT $=$ Narrative vs. Flowchart

Research question (RQ) 2 relates to the incremental value of using a second documentation format. It asks whether using flowchart or narrative as a second documentation tool will increase the total quantity of detected system control errors, regardless of whether the flowchart or narrative was used to document the controls initially. RQ2 was examined by conducting two separate GLM analyses. The first analysis involves determining the incremental value of narrative by deducting errors detected by the flowchart portion of the "flowchart first then narrative" sequence from total detected errors in this sequence (or $\mathrm{Y}-\mathrm{D}>0$ ) as shown in Table 1 . The second method involves determining the incremental value of flowchart by deducting errors detected by the narrative portion of the "narrative first then flowchart" sequence from total detected errors in this sequence (or $\mathrm{Z}-\mathrm{E}>0$ ). The incremental value of narrative over flowchart was significant $(F=12.25 ; \mathrm{p}<.003)$ and the incremental value of flowchart over narrative was also significant $(\mathrm{F}=9.6 ; \mathrm{p}<.0068)$, suggesting that additional errors will be detected by using more than one format to document an accounting information system. The results are presented in Table 3 panel B and panel C respectively.

Research Question (RQ) 3 asks whether using the (B-O) documentation sequence to document a system would detect more errors than using the narrative then flowchart (N-F) or the flowchart then narrative (F-N) sequence. It further asks whether documenting a system using the F-N sequence would result in detecting more system control errors than using the (N-F) sequence method, that is, does detection performance follow the order of $\mathrm{X}>\mathrm{Y}>\mathrm{Z}$ ? The results reveal no significant main effect of sequence as shown in Table $3(\mathrm{~F}=0.59 ; \mathrm{p}>.559)$ as indicated in Table 3 panel D. The means for the (B-O) sequence (see Table 2) is not larger than that of the (F-N) sequence, although it is larger than that of $(\mathrm{N}-\mathrm{F})$ sequence.

Research Question RQ4 relates to the interaction effect between documentation format and sequence, implying that the amount of detected system errors will depend upon the documentation format and sequence used to document the accounting information system. The results in Table 3 panel D show a significant interaction of documentation format and sequence $(F=16.50 ; \mathrm{p}<.000)$. An observation of the means in Table 2 shows clear differences in the amount of errors detected by each documentation sequence in relation to each specific documentation format. Further analysis using the Tukey's T-test for multiple comparison indicates that the means for each documentation sequence are significantly different $(T=3.45, \mathrm{p}<.05)$ primarily only for the flowchart documentation format but not the narrative documentation format. These comparisons are presented in Table 4, panels A and B. Other analysis for the effect of class level, such as graduate versus undergraduate class level was not significant. 
Table 4: General Linear Model Test Results Multiple Comparisons (Tukey)

Panel A

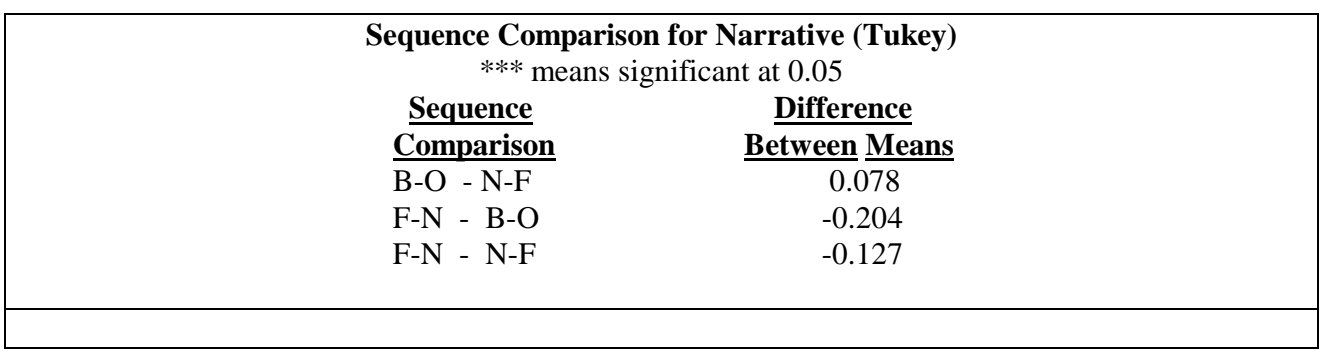

Panel B

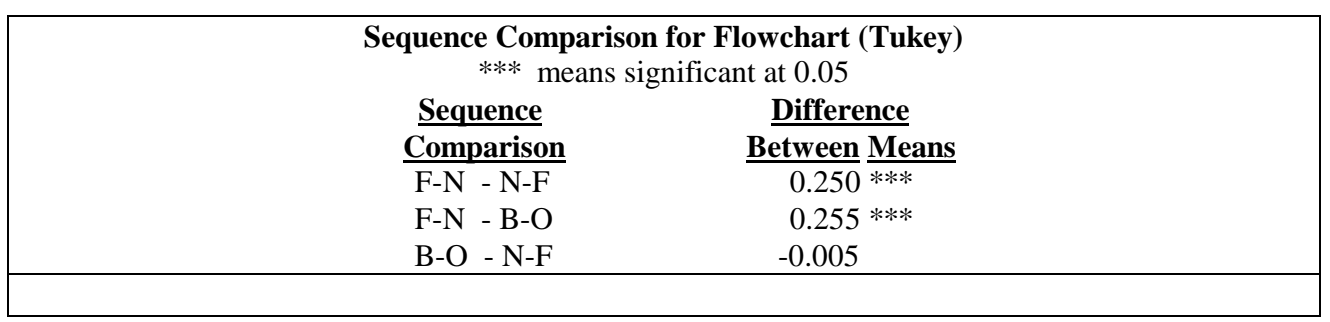

\subsection{Discussion and Conclusion}

The results of this experiment suggest that using two or more documentation formats in evaluating a client's accounting information system controls has incremental value, because each documentation format addresses different aspect of the evaluation task. The participants in this study detected more total errors when they documented the sales returns accounting information system using narratives and flowcharts. However, detection performance also depended upon the sequence that documentation formats were used. Subjects using the flowchart first before narrative seem to detect more errors than subjects using both narrative and flowchart combined than those using narrative first before flowchart.

As shown in Table I, the results also show a strong interaction of documentation format and sequence in that the subjects detected more errors with the documentation format they seem to use first. For example, when the sequence was (F-N), the participants' detected performance was 31 percent when documenting the system with flowchart compared to 23 percent detection with the narrative. Similarly, when the documentation sequence was (NF), subjects detected 36 percent of the system control errors with the narrative compared to six percent detection with the flowchart. Finally, subjects who received the two documentation formats together acted as if they received the narrative first because they detected 44 percent of the errors with the narrative compared to only five percent with the flowchart. Although the detection performance in $(\mathrm{B}-\mathrm{O})$ is more than that of $(\mathrm{N}-\mathrm{F})$, this was not significant.

Overall, the detection performance was very low. This was probably due to the students' confidence level in using narrative and flowchart as documentation tools. The individual confidence level for the flowchart and narrative was 57 percent and 53 percent respectively, but their overall confidence that they detected control weaknesses and errors in the accounting information system was 57 percent. These levels of confidence are consistent with the level of error detection reported in this study.

This study has some limitations. The subjects are students and are inexperienced in documenting actual accounting information systems or deciding which documentation format is likely to being more effective tool for the specific accounting information system. Another limitation is that it was not quite clear whether the subjects in the (B-O) sequence actually followed the instructions to use an " $\mathrm{N}$ " and " $\mathrm{F}$ " notations to describe the errors they 
detected from the Narrative or Flowchart sections of the experiment. If they did not, this might affect the findings reported here. Additional analysis was conducted to mitigate this limitation by excluding data from the (B-O) sequence portion of the experiment. However, the significance of the reported results did not change. Another limitation is in regard to the sample size used in this study, which was small. A larger sample size could have an impact of the validity of the findings.

\subsection{Suggested Future Research}

Research could further investigate whether the observed effects using accounting and accounting information systems students would be observed if experienced internal auditors were used as participants. Additionally, researchers could use more complex systems scenarios to simulate whether system documentation performance depends upon the format and documentation sequence.

\section{References}

1 Arnold, V., P. Collier., S.A. Leech, and SS. Sutton, "The Effect of Experience on Order and Recency Bias in Decision Making by Professional Accountants," Accounting and Finance N0. 40 pp. 107-132, 2000.

2. American Institute of Certified Public Accountants, Statement on Auditing Standards No. 78, Consideration of Internal Control in a Financial Statement Audit, AICPA, New York, 1996.

3. Anderson, N., Foundations in Integration Theory, Academy Press, New York, New York, 1981

4 Arens, A.A and J.K. Loebbecke, Auditing: An Integrated Approach, $7^{\text {th }}$ Edition, Prentice Hall, Englewood Cliffs, NJ, 1997.

5. Bierstaker, J.L, "Performance in Internal Control Evaluation: The Importance of the Documentation Format and Domain Knowledge," Ph.D Dissertation, University of Connecticut, 1995.

6. Bierstaker, J.L. and R. Brody, "A Comparison of Internal and External Auditors Choice of Internal Control Documentation Format," The Auditor's Report, Winter, pp. 10-10, 2000.

7. Curtis, M. B and A.F. Borhick, "Evaluation of Internal Controls from a Control Objective Narrative," Journal of Information Systems, Spring, pp. 63-82, 1999.

8 Curtis, M. B, and R.E. Viator, "An Investigation of Multidimensional Knowledge Structure and Computer Auditor Performance," Auditing: A Journal of Practice and Theory, Fall, pp. 83-103, 2000.

10. Davis, J.T., "Experience and Auditors' Selection of Relevant Information for Preliminary Control Risk Assessments," Auditing: A Journal of Practice and Theory, Spring, pp. 16-37, 1996.

11. Gelinas, U.J., S. G. Sutton, and A.E. Oram, Accounting Information Systems, Fourth Edition, South-West College Publishing, New York, New York, 1998.

12. Hogarth, R. and H. Einhorn, "Order Effects in Belief updating: The Belief Adjustment Model" Cognitive Psychology, No. 24, pp. 1-55, 1992

13. Monroe, G.S., and J. Ng,, "An examination of Order Effects in Auditor Inherent Risk Assessments," Accounting and Finance, No. 40, pp. 153-168, 2000.

14. Newell, A. and H. Simon, Human Problem Solving, Prentice-Hall, Englewood Cliffs, New Jersey, 1972.

15. Payne, J.W., J.R. Bettman and E.J. Johnson, "The Adaptive Decision Maker: Effort and Accuracy in Choice," in R.M. Hogarth, ed., Insights in Decision Making, University of Chicago Press, Chicago, Illinois, 1990.

16. Plumlee, R.D, "The Standard of Objectivity for Internal Auditors: Memory and Bias Effects," Journal of Accounting Research. No. 23, pp. 683-699, 1985.

17. Purvis, S.E.C, "The Effect of Audit Documentation Format on Data Collection," Accounting Organization and Society, No. 14, pp. 551-63, 1989.

18. Wallace, W. A, Auditing, $3^{\text {rd }}$ Edition, South Western College, Cincinnati, Ohio, 1995.

\section{Endnotes}

i Gelinas, Sutton, and Oram (1998) suggests that the ability of the auditor to create and understand flowcharts and narratives is an integral part of being proficient.

ii While recency effect occurs when variables presented later in a sequence have a greater effect on the decision maker, primacy effect occurs when variables presented earlier have a greater effect on the decision maker (Anderson 1981). 